Research Article

\title{
Cellulose Conversion to 5 Hydroxymethyl Furfural (5-HMF) Using Al-Incorporated SBA-15 as Highly Efficient Catalyst
}

\author{
Son Tung Pham, ${ }^{1,2}$ Manh B. Nguyen $\mathbb{D}^{1,3}$ Giang H. Le ${ }^{10},{ }^{1}$ Trang T. T. Pham, ${ }^{1,4}$ \\ Trang T. T. Quan $\mathbb{D}^{1},{ }^{1}$ Trinh Duy Nguyen $\mathbb{D}^{5},{ }^{5}$ Thanh Le Son $\mathbb{D}^{2},{ }^{2}$ and Tuan Anh Vu $\mathbb{D}^{1,4}$ \\ ${ }^{1}$ Institute of Chemistry, Vietnam Academy of Science and Technology (VAST), 18 Hoang Quoc Viet, Cau Giay, Hanoi, Vietnam \\ ${ }^{2}$ Hanoi University of Science (HUS), Vietnam National University (VNU), 334 Nguyen Trai, Hanoi, Vietnam \\ ${ }^{3}$ Institute of Research and Development, Duy Tan University, Da Nang 550000, Vietnam \\ ${ }^{4}$ Graduate University of Science and Technology, Vietnam Academy of Science and Technology, 18 Hoang Quoc Viet Street, \\ Cau Giay, Ha Noi, Vietnam \\ ${ }^{5}$ NTT Institute of High Technology, Nguyen Tat Thanh University, 300A Nguyen Tat Thanh, District 4, \\ Ho Chi Minh City, Vietnam
}

Correspondence should be addressed to Thanh Le Son; lethanhson@yahoo.com and Tuan Anh Vu; vuanhtuan.vast@gmail.com

Received 14 March 2019; Revised 1 June 2019; Accepted 2 July 2019; Published 7 August 2019

Academic Editor: Elena Gomez

Copyright (c) 2019 Son Tung Pham et al. This is an open access article distributed under the Creative Commons Attribution License, which permits unrestricted use, distribution, and reproduction in any medium, provided the original work is properly cited.

\begin{abstract}
Al-incorporated SBA-15 samples (xAl/SBA-15) were successfully prepared by "atomic implantation" method. The samples were characterized by X-ray diffraction spectroscopy (XRD), transmission electron microscopy (TEM), energy-dispersive X-ray spectroscopy (EDX), $\mathrm{N}_{2}$ adsorption-desorption isotherms (BET), and temperature-programmed desorption ( $\left.\mathrm{NH}_{3}-\mathrm{TPD}\right)$. In this catalyst, metal oxide species were highly dispersed on the SBA-15 surface and existed as isolated atoms. It was shown that the Al incorporation lead to the formation of medium and strong acid sites. The catalytic activity and selectivity were tested in a mild hydrothermal process for degradation of cotton cellulose to 5-hydroxymethyl furfural (5-HMF). A cellulose conversion of $68.5 \%$ and 5 -HMF selectivity of $62.1 \%$ after $2 \mathrm{~h}$ of reaction at $170^{\circ} \mathrm{C}$ were achieved. The very high 5 -HMF yield (42.57\%) obtained in this paper is much higher than that was reported in the literature.
\end{abstract}

\section{Introduction}

In recent years, the process of biomass conversion to hydrocarbon fuels has received much attention due to the limited fossil fuels resource, demanding the alternatives to obtain biofuels. Biomass is as well known as carbon renewable energy resources for the production of bio-oil by the fast pyrolysis technology. However, bio-oil is composed of different compounds with high oxygen content and low chemical stability and, therefore, cannot be used as biofuels. Recently, great efforts have been made to develop practical pathways to transform biomass-derived carbohydrates into chemicals and fuels. 5-Hydroxymethyl furfural (5-HMF) has a versatile range of applications and can be obtained from the chemical conversion of $\mathrm{C}_{6}$ carbohydrates. The conversion of cellulosic biomass to valuable chemicals such as 5-hydroxymethyl furfural, which is often termed the "sleeping giants," is currently one of the most interests of worldwide research and developments to foster a biobased economy [1]. Therefore, considerable efforts devoted to the depolymerization of cellulose to obtain 5-HMF as a promising bio-oil.

Due to its high degree of crystallinity and stability, hydrolysis of cellulose was often carried out in acidic medium using acids like $\mathrm{H}_{2} \mathrm{SO}_{4}, \mathrm{HCl}$, and $\mathrm{HF}$. In the rigorous reaction condition, the experimental equipment must have high corrosion resistance. Besides, high concentration of inorganic acid used in the reaction can cause extremely negative impacts on surrounding environment. Conversion of cellulose to 5-HMF by using solid acid catalysts under 
hydrothermal conditions is an environment-friendly chemical process, and it is easy to separate products by filtration. Interestingly, after the reaction, the catalyst can be easily recovered and reused. The $\mathrm{SO}_{4}{ }^{2-} / \mathrm{ZrO}_{2}-\mathrm{Al}_{2} \mathrm{O}_{3}$ catalysts were employed in glucose hydrolysis in hot water which led to a 5-HMF conversion 39\% [2]. Zhang et al. stated the preparation of $\mathrm{SO}_{4}{ }^{2-} / \mathrm{ZrO}_{2}$ on $\mathrm{TiO}_{2}$ and showed high conversion of glucose into 5-HMF [3]. The combined yield of 5-HMF and levulinic acid reached $28.8 \%$ in the presence of $\mathrm{SO}_{4}{ }^{2-} / \mathrm{ZrO}_{2}-\mathrm{TiO}_{2}$ when the $\mathrm{Zr}$ : Ti molar ratio was 5:5 after $2 \mathrm{~h}$ of reaction at $170^{\circ} \mathrm{C}$.

The advantage of the use of SBA-15 material as catalyst support includes its well-ordered hexagonal mesoporous silica structure with high surface-to-volume ratio, high permeability, variable framework compositions, and high thermal stability [4-6]. However, the electrically neutral framework of purely siliceous SBA-15 gives a rise to its lack of functionality. As a result, it normally plays a role of adsorbent, not acidic or redox catalysts $[7,8]$. In order to be used as acidic or redox catalysts, SBA-15 should be modified by incorporation of transition metals into framework using direct and/or postsynthesis [9-17]. Aluminium ions $\left(\mathrm{Al}^{3+}\right)$ insertion into the SBA-15 creates acid sites in the structure which is extremely important for acid-catalyzed reaction. However, the incorporation of aluminium into $\mathrm{Al} / \mathrm{SBA}-15$ is difficult because of the difference in hydrolysis rates of $\mathrm{Al}$ and $\mathrm{Si}$ in low $\mathrm{pH}$ medium during the SBA-15 synthesis process [18]. Various synthetic methods have been devoted for the incorporation of higher amounts of aluminium to achieve higher acid sites $[14,16,17]$.

In this paper, we report a novel method to incorporate aluminium ion into the SBA-15 framework by atomic implantation and use it as an efficient catalyst for conversion of cellulose to HMF. Effects of reaction temperature and catalyst dosage were also investigated.

\section{Experimental Methods}

2.1. Preparation of SBA-15. Synthesis of SBA-15 material was done as follows: $1 \mathrm{~g}$ of poly (ethylene glycol)-block-poly (propylene glycol)-block-poly (ethylene glycol) (P123) was dissolved in $60 \mathrm{~mL}$ of $\mathrm{HCl}(2 \mathrm{M})$ and stirred for few hours until a clearly surfactant solution was obtained. Sodium silicate solution $\sim 27 \% \mathrm{SiO}_{2}$ (Sigma-aldrich) was added dropwise into the surfactant solution with vigorous stirring for 2 hours; then, the mixture was further stirred for 24 hours at $45^{\circ} \mathrm{C}$, and the obtained mixture was poured into Teflon lined and autoclave hydrothermal treatment was performed in an oven at $100^{\circ} \mathrm{C}$ for $24 \mathrm{~h}$. Finally, the white solid product was washed, dried at $80^{\circ} \mathrm{C}$ overnight, and calcined at $550^{\circ} \mathrm{C}$ for $6 \mathrm{~h}$ in air.

2.2. Preparation of $x A l / S B A-15$. Al incorporate was carried out by atomic implantation method using $\mathrm{AlCl}_{3}$ (99,99\%, Sigma-aldrich) as Al source [19]. In order to obtain 1 Al/ SBA-15 with different $\mathrm{Al}$ loading, we deposited $\mathrm{Al}$ by repeating the $\mathrm{Al}$ deposition time. $\mathrm{AlCl}_{3}$ first deposited on SBA15 which was prepared previously (denoted $1 \mathrm{Al} / \mathrm{SBA}-15$ sample). Use of $1 \mathrm{Al} / \mathrm{SBA}-15$ as starting material, we deposited the second $\mathrm{Al}$ layer on $1 \mathrm{Al} / \mathrm{SBA}-15$ to obtain $2 \mathrm{Al} /$ SBA-15 and use of 2Al/SBA-15 as starting material we deposited the third Al layer (denoted 3Al/SBA-15 sample). The reactor was a quartz tube $(2 \mathrm{~cm} \times 25 \mathrm{~cm})$ in which amount of $\mathrm{AlCl}_{3}$ was introduced on one side and an opposite side placed a determined amount of SBA- 15 .

Reactor was heated to $350^{\circ} \mathrm{C}$, and $\mathrm{AlCl}_{3}$ evaporated and passed through substrate of SBA-15 by flowing carrier gas $\left(\mathrm{N}_{2}\right)$. The reaction time was varied between $0.5 \mathrm{~h}$ to $1 \mathrm{~h}$. Then the sample was calcined at $500^{\circ} \mathrm{C}$ to remove chloride.

2.3. Characterization of Materials and Membrane. The morphology characteristics of the materials were analyzed by transmission electron microscopy (HITACHI-H-7500). The pore structure of all resulting solids was determined by nitrogen adsorption-desorption isotherms at $77 \mathrm{~K}$ using TriStar Plus II. The powder X-ray diffraction patterns of the samples were recorded on a D8 Advance analyzer with $\mathrm{Cu}$ $\mathrm{K} \alpha$ radiation $(l=1.5417 \AA)$. The chemical composition of the samples was analyzed by EDX, on JED-2300 analysis Station (JEOL) machine. The acid sites were measured by using $\mathrm{NH}_{3}$-TPD (model: Autochem II). The ammonia concentration in the effluent gases was determined by a thermal conductivity detector.

2.4. Catalytic Test. The investigation of catalytic degradation of cotton cellulose was carried out in a high-pressure batch stainless-steel reactor equipped with a liner of polytetrafluoroethylene (PTFE). The cotton cellulose, solid acid catalysts, and water were thoroughly mixed in the reactor; then, the mixture was heated in the oven. Some effects of operation parameters were mainly investigated such as catalyst type and dosage, reaction temperature, and time on the cellulose saccharification to glucose and the monosaccharide dehydration to 5-HMF. After the reaction, the mixture of solution and solid reactants were separated by filtration.

The cellulose conversion, selectivity, and yield 5-HMF were calculated by the following equation:

$$
\begin{aligned}
\text { cellulose conversion }(C \%) & =\frac{\text { reacted cellulose }}{\text { initial cellulose }} \times 100 \%, \\
5 \text {-HMF selectivity }(S \%) & =\frac{5-\text { HMF }}{\text { reacted cellulose }} \times 100 \%, \\
5-\mathrm{HMF}-\text { Yield }(Y \%) & =C(\%) \times S(\%) .
\end{aligned}
$$

\section{Results and Discussion}

3.1.X-Ray Diffraction Spectroscopy (XRD). Figure 1(a) shows the low-angle X-ray diffraction patterns of xAl/SBA-15. In the XRD pattern, the one peak with strong intensity in the $2 \theta$ angle of $\sim 1.02^{\circ}$, two peaks with weak intensity at $2 \theta$ angle of $\sim 1.6^{\circ}$ and $2 \theta \sim 1.8^{\circ}$, corresponding to the diffraction of (100), (110), and (200) reflection, respectively, which are characteristic for the structure of $2 \mathrm{D}$ hexagonal $p 6 \mathrm{~mm}$ symmetry of mesoporous SBA-15 structure $[19,20]$. In the 


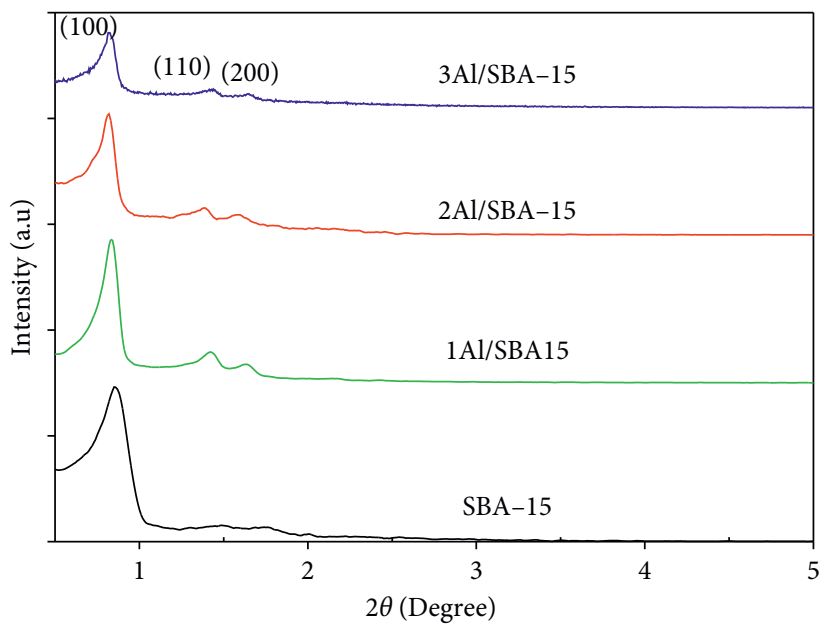

(a)

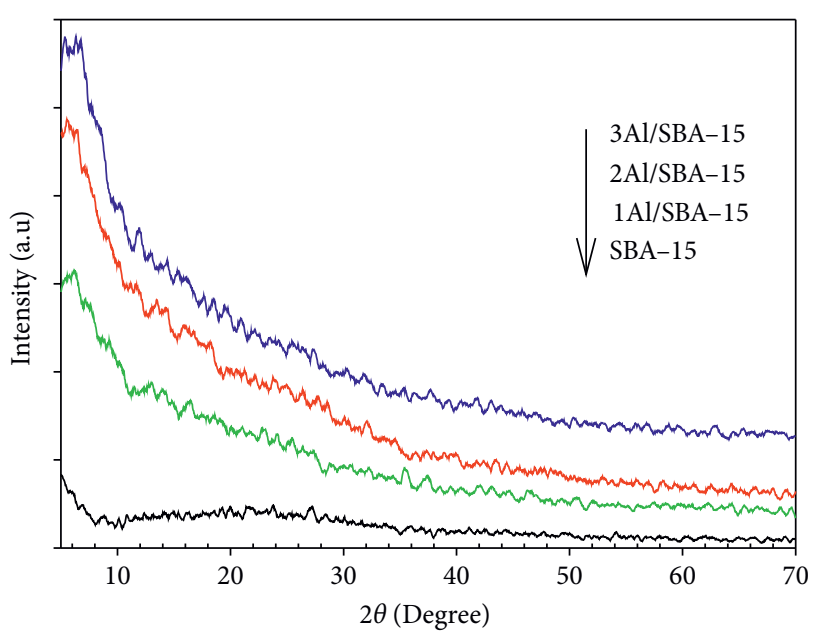

(b)

Figure 1: Small angle (a) and wide angle (b) XRD patterns of SBA-15 and xAl/SBA-15.

wide angle (Figure 1(b)) XRD pattern of the $\mathrm{xAl} / \mathrm{SBA}-15$, no diffraction lines of crystalline $\mathrm{Al}$ oxide in $\mathrm{xAl} / \mathrm{SBA}-15$ samples were observed. This can be explained by the fact that almost all $\mathrm{Al}$ incorporated into SBA-15 framework; therefore, the phase of $\mathrm{Al}_{2} \mathrm{O}_{3}$ could not be detected by [5].

As shown in Table 1, the Rietveld refined parameter of the crystal structure of these samples was slightly changed with different $\mathrm{Al}$ incorporated into SBA-15 framework. This is related to the substitution of metal ions $(\mathrm{Al})$ for $\mathrm{Si}$ in the SBA-15 framework. Because the ionic radius of $\mathrm{Al}^{3+}(0.51 \AA)$ is greater than $\mathrm{Si}^{4+}(0.41 \AA)$, the $\mathrm{Al}-\mathrm{O}$ bond lengths are longer than $\mathrm{Si}-\mathrm{O}$ bond, leading to increase in $d_{100}$ and $a_{0}$ parameters $[7,17,21]$. This result strongly confirms that $\mathrm{Al}$ incorporation into SBA-15 framework.

3.2. $\mathrm{N}_{2}$ Adsorption-Desorption Isotherms (BET). Figure 2 shows the $\mathrm{N}_{2}$ isotherms and pore size distribution of calcined SBA-15 and xAl/SBA-15. It can be seen from $\mathrm{N}_{2}$ isotherms of these samples that the hysteresis loops indicated the typical feature of mesoporous materials owing to the capillary condensation. The increase in $\mathrm{N}_{2}$ amount adsorbing on the material is clearly observed which is resulted from the multilayer adsorption in the formed mesopore $[16,19]$. This indicates that the samples have a large pore size $(5.5 \mathrm{~nm}$ for SBA- 15 and $5.5-5.8 \mathrm{~nm}$ for $\mathrm{xAl} /$ SBA-15). The high degree of mesopore ordering leads a sharp inflection at relative pressures $\left(P / P_{0}\right)$ between 0.6 and 0.8 which is consistent with well-defined $3 \mathrm{~nm}$ mesopores. The BET surface areas of SBA-15 and xAl/SBA-15 (Table 2) were strongly decreased from $668 \mathrm{~m}^{2} / \mathrm{g}$ to $143 \mathrm{~m}^{2} / \mathrm{g}$, respectively. This result can be explained that the new small $\mathrm{Al}$ oxides particles were formed and located along to the channels, causing the decrease of surface area. As seen in Table 2, the SBA-15 sample had a pore diameter of $5.50 \mathrm{~nm}$ and a wall thickness of $5.51 \mathrm{~nm}$, while xAl/SBA-15 samples showed a slight increase of pore diameter and wall thickness. This result clearly indicated that the new mesopore system
TABLE 1: Characterization of the crystal structure of all samples.

\begin{tabular}{lcc}
\hline Samples & $D_{100}(\AA)$ & $a_{0}(\mathrm{~nm})\left(a_{0}=2 . d_{100} / \sqrt{ } 3\right)$ \\
\hline SBA-15 & 95.419 & 11.01 \\
1Al/SBA-15 & 100.356 & 11.58 \\
2Al/SBA-15 & 101.276 & 11.69 \\
3Al/SBA-15 & 102.542 & 11.84 \\
\hline
\end{tabular}

was formed and located along to the pore SBA-15 system $[11,22]$.

3.3. Transmission Electron Microscopy (TEM) and EnergyDispersive X-Ray Spectroscopy (EDX). The transmission electron microscopy (TEM) images of SBA-15 and xAl/SBA15 samples are illustrated in Figure 3. The TEM image of SBA-15 display well-ordered hexagonal arrays of mesopore with one-dimensional channels, indicating a $2 \mathrm{D}$ hexagonal $(p 6 \mathrm{~mm})$ mesostructure. The average wall thickness was $\sim 5-$ $6 \mathrm{~nm}$, with similar width pore diameters determined by BET. As seen in Figures 3(b)-3(d), the pore and wall thickness of $\mathrm{Al}$ incorporated SBA- 15 were not uniform as compared to those of pure SBA-15. Especially, for the Al-incorporated SBA-15 sample with high Al content (3Al/SBA-15), Al oxide particles covered the surface, no pores and wall of SBA-15 were observed.

The results of EDX in Figure 4 and Table 3 show that the $\mathrm{Al}$ element contents (5.6, 9.7, and 12.5\%) deposited on the $\mathrm{xAl} / \mathrm{SBA}-15$ were approximately equal to the value calculated. From Figure 4, it was noted that the Al loading was increasing. Thus, at high $\mathrm{Al}$ loading (3Al/SBA-15), the intensity of $\mathrm{Al}$ peak was higher than that of medium loading sample (2Al/SBA-15). However, when Al content was too high, $\mathrm{Al}$ content determined by EDX is lower than calculated amount. This due to the saturation of Al deposited on SBA15 surface. The 3Al/SBA-15 sample was prepared by deposition the third $\mathrm{Al}$ layer on $2 \mathrm{Al} / \mathrm{SBA}-15$ sample. In this case, penetration of $\mathrm{Al}$ into $\mathrm{SBA}-15$ is hindered by the two $\mathrm{Al}$ 


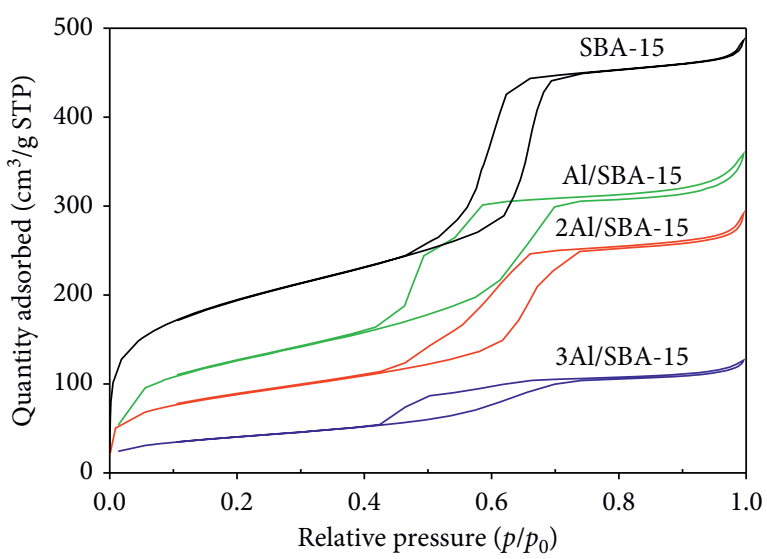

(a)

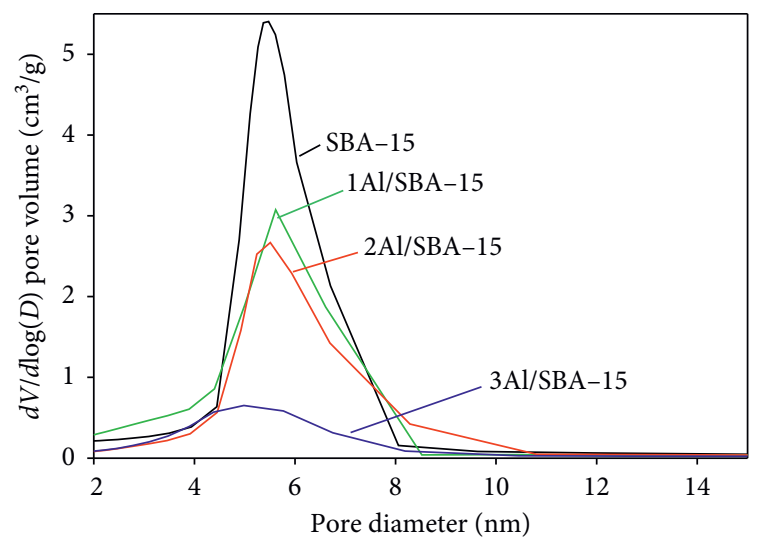

(b)

FIgURe 2: BET specific surface area of SBA-15 and xAl/SBA-15 samples (a) and pore size distribution (b).

TABLE 2: Textual characteristics of SBA-15 and xAl/SBA-15 samples.

\begin{tabular}{lccccc}
\hline Samples & $S_{\text {BET }}\left(\mathrm{m}^{2} / \mathrm{g}\right)$ & $S_{\text {micro }}\left(\mathrm{m}^{2} / \mathrm{g}\right)$ & $V_{\text {pore }}\left(\mathrm{cm}^{3} / \mathrm{g}\right)$ & $D_{\mathrm{BJH}}(\mathrm{nm})$ & $W_{\mathrm{t}}(\mathrm{nm}) W^{\prime} a_{0}-\mathrm{D}_{\mathrm{BJH}}$ \\
\hline SBA-15 & 668.52 & 182.93 & 0.70 & 5.50 & 5.51 \\
1Al/SBA-15 & 443.05 & 127.61 & 0.55 & 5.54 & 5.90 \\
2Al/SBA-15 & 309.16 & 87.07 & 0.44 & 5.76 & 5.93 \\
3Al/SBA-15 & 143.39 & 43.75 & 0.19 & 5.80 & 6.04 \\
\hline
\end{tabular}

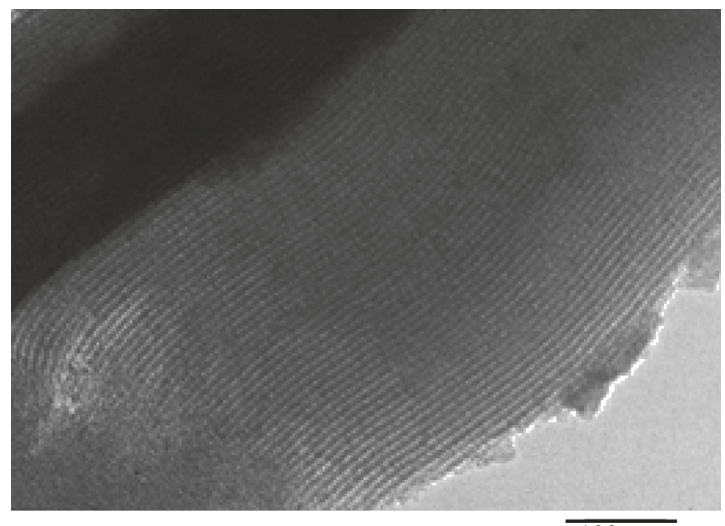

$\overline{100 \mathrm{~nm}}$

(a)

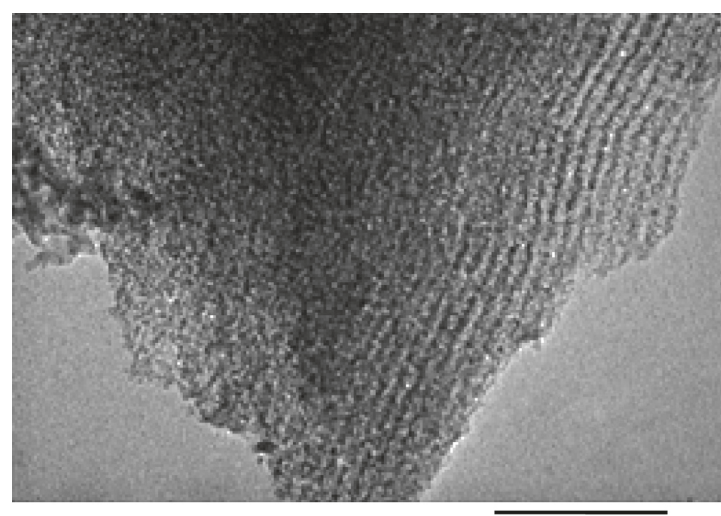

$100 \mathrm{~nm}$

(c)

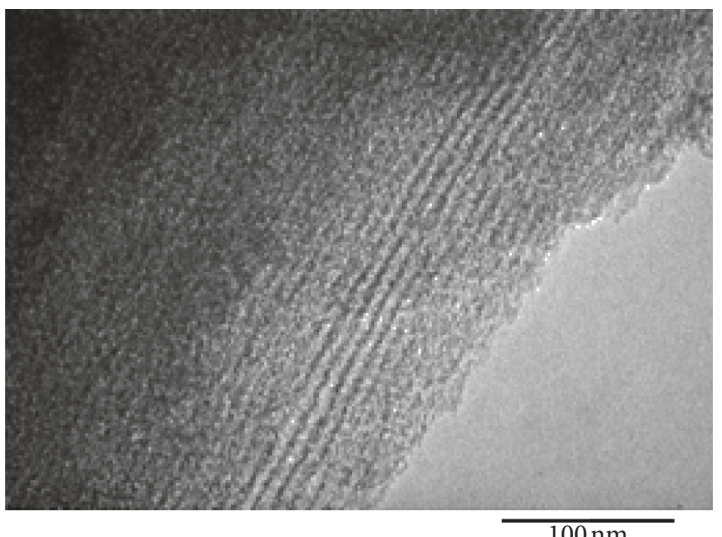

(b)

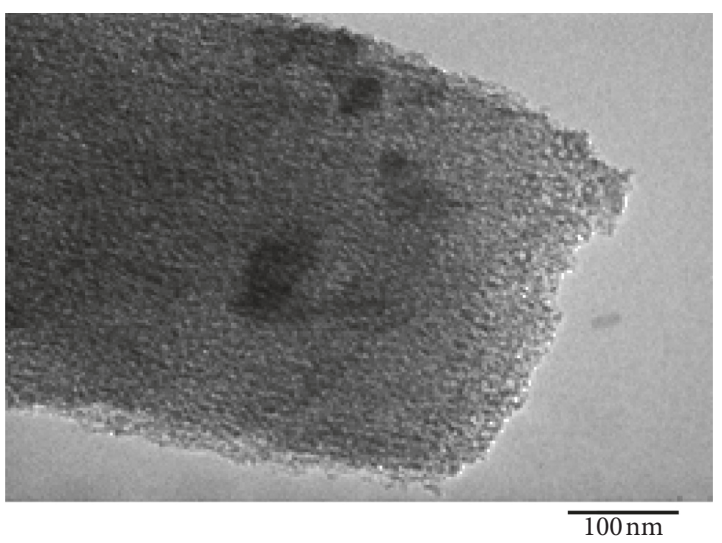

(d)

Figure 3: TEM images of (a) SBA-15 and (b) xAl/SBA-15, (c) xAl/SBA-15, and (d) xAl/SBA-15. 


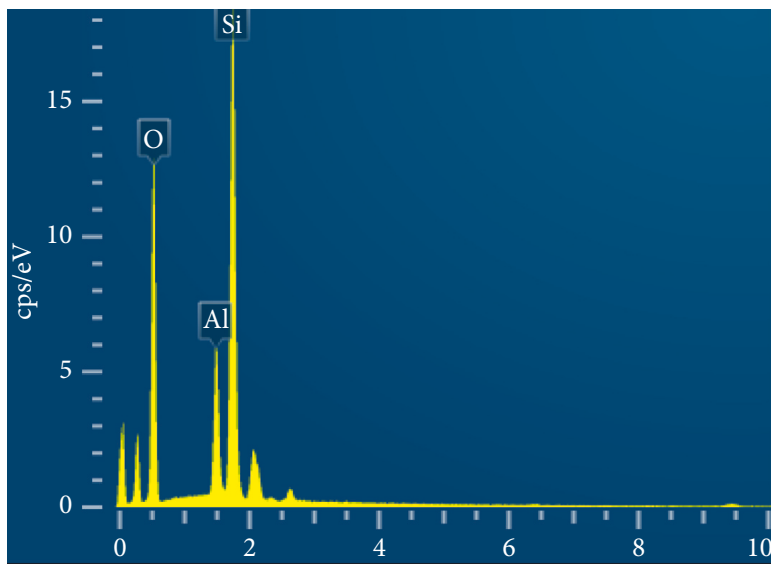

(a)

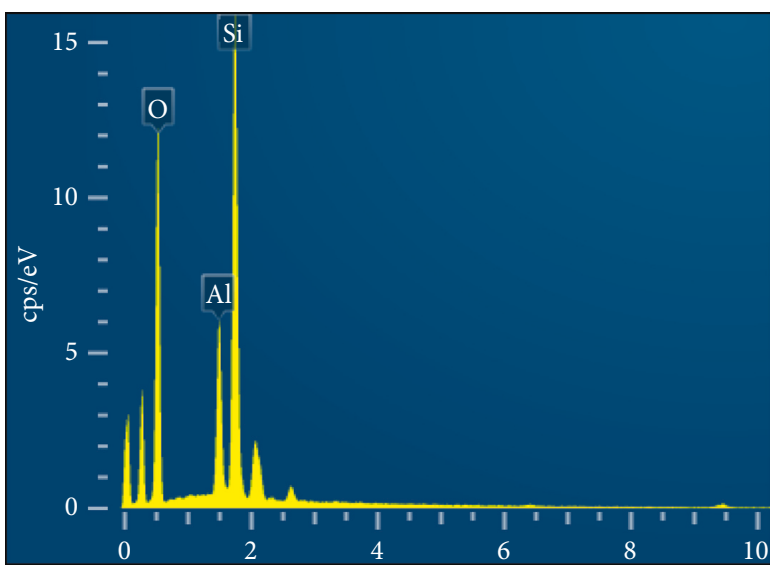

(b)

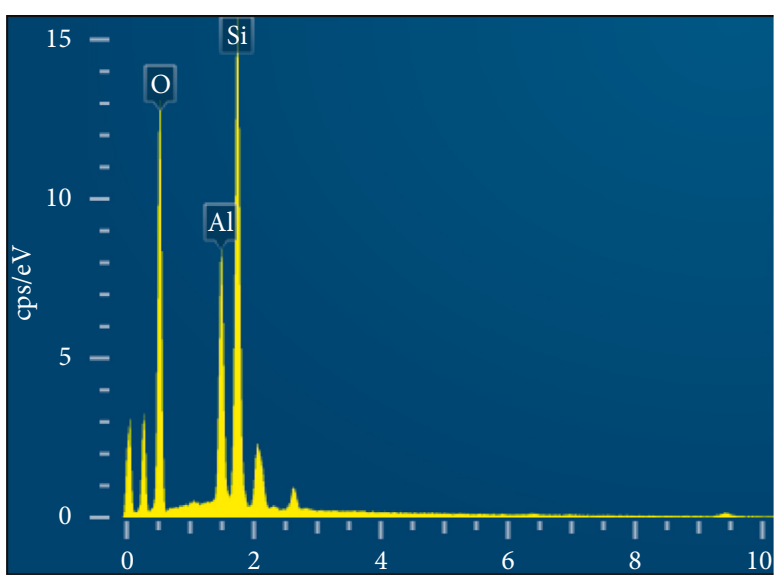

(c)

Figure 4: EDX of Al/SBA-15 (a), 2Al/SBA-15 (b), and 3Al/SBA (c).

TABLE 3: EDX result $\mathrm{Si}, \mathrm{O}$, and $\mathrm{Al}$ content in $\mathrm{xAl} / \mathrm{SBA}-15$.

\begin{tabular}{lccc}
\hline \multirow{2}{*}{ Samples } & \multicolumn{3}{c}{ Weight (\%) } \\
& $\mathrm{O}$ & $\mathrm{Si}$ & $\mathrm{Al}$ \\
\hline SBA-15 & 63.19 & 36.81 & - \\
1Al/SBA-15 & 63.44 & 30.91 & 5.66 \\
2Al/SBA-15 & 61.39 & 28.92 & 9.70 \\
3Al/SBA-15 & 60.67 & 26.78 & 12.56 \\
\hline
\end{tabular}

layers which previously deposited on SBA-15, leading to the saturation.

3.4. Temperature-Programmed Desorption ( $\mathrm{NH}_{3}$-TPD). It is well known that cellulose hydrolysis is catalysized the by acid catalyst. The cellulose conversion is strongly depended on the acidity of the catalysts. To determine the acidity of $\mathrm{Al}$ incorporated SBA-15, we used the $\mathrm{NH}_{3}$-TPD method [14]. Figure 5 shows $\mathrm{NH}_{3}$-TPD profiles of $\mathrm{Al}$ incorporated SBA15. Amounts of weak $\left(<200^{\circ} \mathrm{C}\right)$, medium $\left(250-300^{\circ} \mathrm{C}\right)$, and strong $\left(500-550^{\circ} \mathrm{C}\right)$ acid sites are listed in Table 4 . As observed in Figure 5 and Table 4, the pure SBA-15 possessed only weak acid sites (max desorption temperature $<200^{\circ} \mathrm{C}$ ), while $\mathrm{Al}$ incorporated SBA-15 samples showed large amount of medium and strong acid sites (Table 4). Among them,

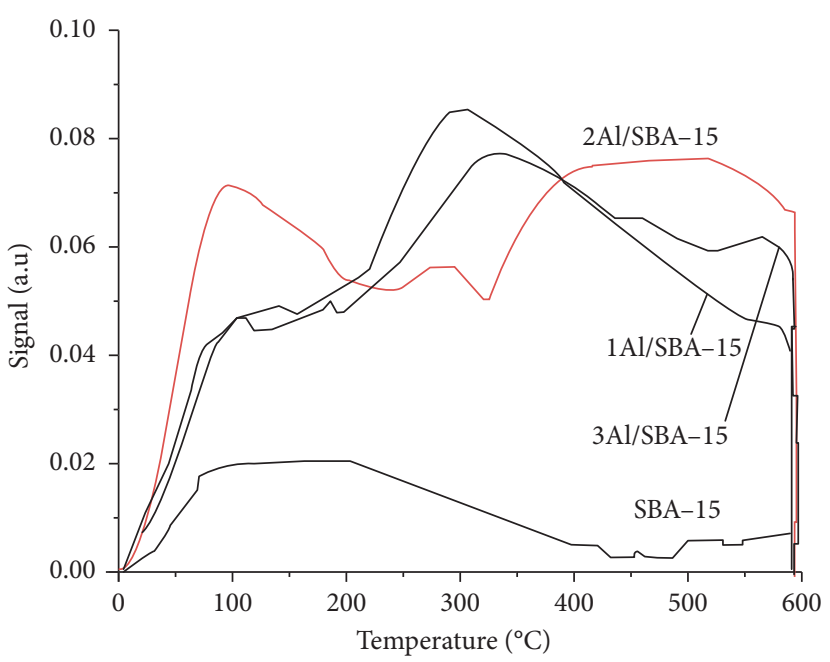

FIgURE 5: $\mathrm{NH}_{3}$-TPD pattern of SBA-15 and xAl/SBA-15 catalyst.

2Al/SBA-15 had the highest amount of medium acid sites ( $\left.T_{\max } \sim 250-300^{\circ} \mathrm{C}\right)$. This may be due to the $\mathrm{Al}$ amount incorporated into SBA-15 is suitable, favoring to form medium and strong acid sistes (isolated $\mathrm{Al}$ sites formation). In the case of $3 \mathrm{Al} / \mathrm{SBA}-15$, amount of acid sites is lower than that of 
TABLE 4: $\mathrm{NH}_{3}$ amount of weak, medium, and strong acid sites of SBA-15 and xAl/SBA-15.

\begin{tabular}{|c|c|c|c|c|}
\hline \multirow{2}{*}{ Samples } & \multicolumn{4}{|c|}{$\mathrm{mol} \mathrm{NH}_{3} / \mathrm{g}$ cat } \\
\hline & $<200^{\circ} \mathrm{C}$ & $250-300^{\circ} \mathrm{C}$ & $500-550^{\circ} \mathrm{C}$ & Total \\
\hline SBA-15 & 0.23 & - & - & 0.23 \\
\hline 1Al/SBA-15 & 0.23 & 0.22 & 0.04 & 0.49 \\
\hline 2Al/SBA-15 & 0.43 & 0.19 & 0.56 & 1.18 \\
\hline $3 \mathrm{Al} / \mathrm{SBA}-15$ & 0.14 & 0.17 & 0.12 & 0.43 \\
\hline
\end{tabular}

TABLE 5: Conversion and selectivity of 5-HMF over xAl/SBA-15 catalyst.

\begin{tabular}{lcccc}
\hline Catalysts & $\mathrm{C}_{5-\mathrm{HMF}}(\mathrm{ppm})$ & $S(\%)$ & $C(\%)$ & $Y(\%)$ \\
\hline 1Al/SBA-15 & 4001.24 & 23.15 & 63.27 & 14.64 \\
2Al/SBA-15 & 10740 & 62.14 & 68.51 & 42.57 \\
3Al/SBA-15 & 7956.02 & 46.03 & 64.49 & 29.68 \\
SBA-15 & 662.6 & 2.92 & 40.15 & 1.17 \\
\hline
\end{tabular}

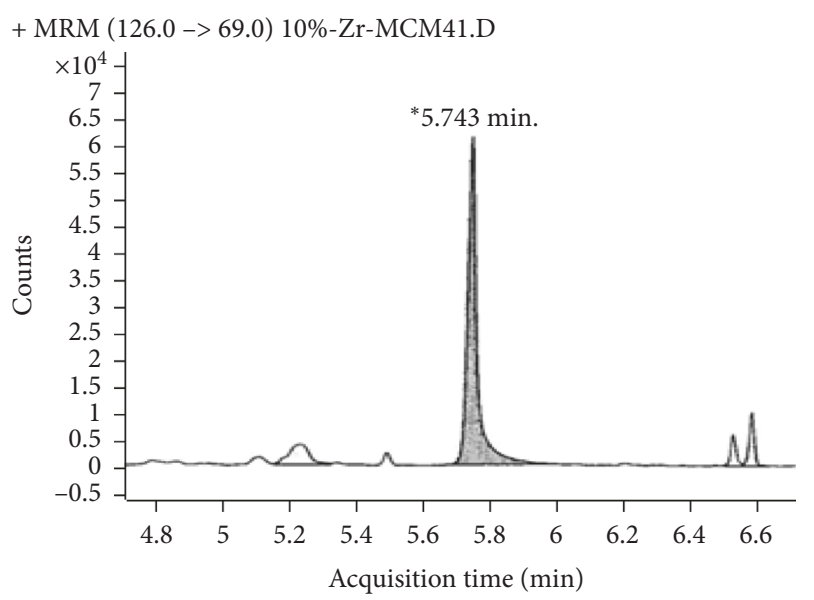

(a)

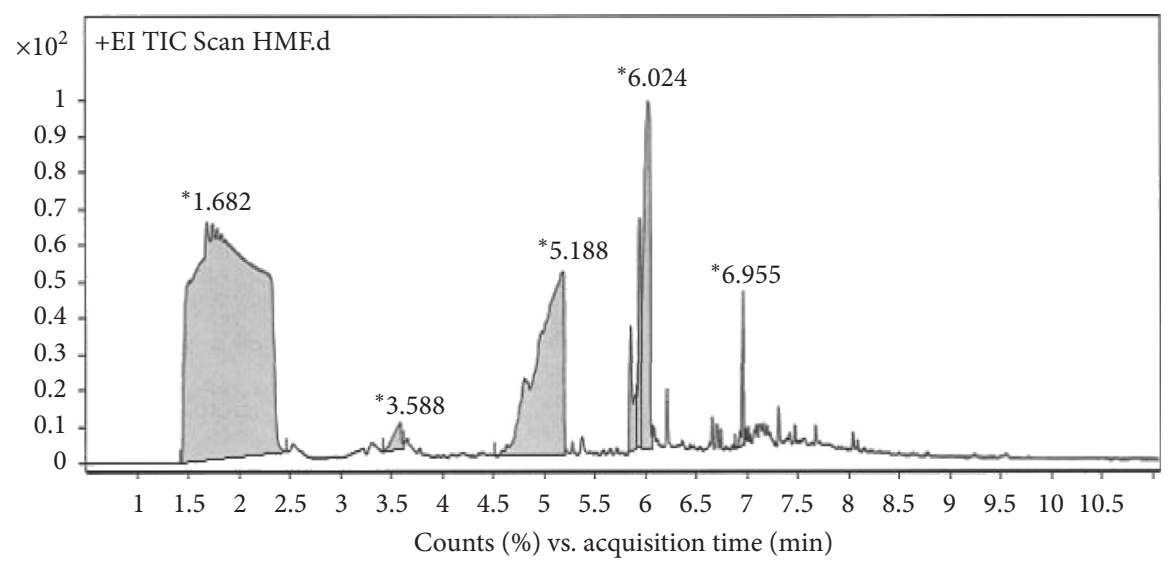

(b)

FIGURE 6: 5-HMF (a) and by-products (b) in the cellulose conversion over Al-incorporated SBA-15 samples.

2Al/SBA-15. This can be explained the formation of $\mathrm{Al}_{2} \mathrm{O}_{3}$ particles which cover the acid sites created after the second Al layer deposition (2Al/SBA-15 sample).

3.5. Catalytic Activity. Table 5 shows that the conversion, selectivity, and yield of 5 HMF over SBA-15 and xAl/SBA-15 catalysts. We have tested the SBA-15 and this showed almost no catalytic activity. Conversion of cellulose to 5-HMF is catalyzed by acid sites since only small amount of weak acid sites in SBA-15 was noted (Table 4). Among Al-incorporated SBA-15 samples, 2Al/SBA-15 catalyst exhibited the highest yield of 5-HMF (42\%). This value was higher than that reported in the literature [23-26]. Some previous works 


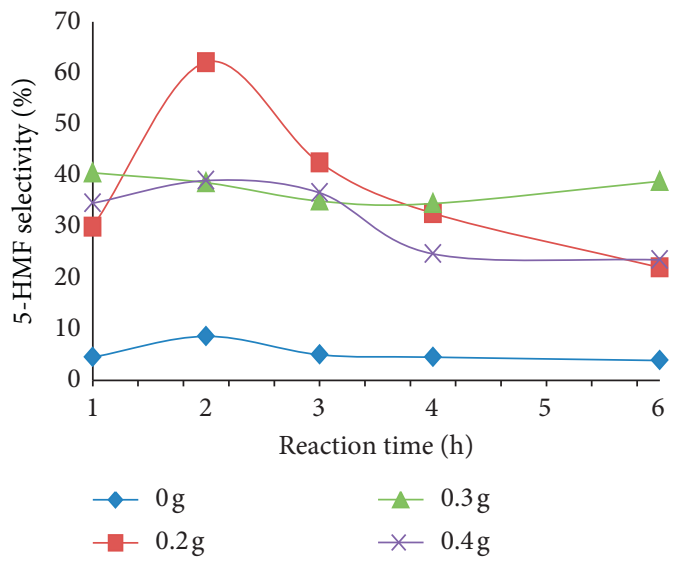

(a)

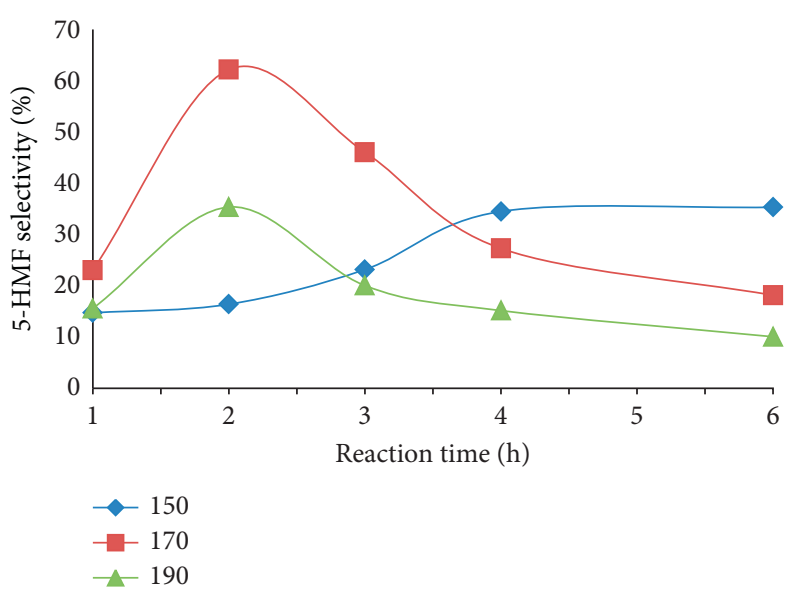

(b)

Figure 7: Effect of catalyst dosage (a) and reaction temperature (b) on the catalytic conversion of cellulose.

stated the low 5-HMF yield (10-20\%). According to the proposed mechanism, cellulose hydrolyzed under the action of a catalyst will be converted into glucose and then isomerized to fructose and fructose followed the hydration convered into 5-HMF $[27,28]$. The process of converting cellulose into glucose requires strong acidic centers, while the isomerization and dehydration process requires medium acidic centers. Therefore, in order to obtain the high 5-HMF from cellulose hydrolysis it needs both the medium and strong acid sites. However, for the sample contained high amount of very strong acid sites like $\mathrm{ZrO}_{2}$ sulfated SBA-15, the cellulose conversion was very high but the 5-HMF selectivity was low due to the formation of intermediate products (result unpublished). This also occurred for Alincorporated SBA-15. Thus, Figures 6(a) and 6(b) illustrate the formation of by-products such as pentanoic acid $\left(\mathrm{C}_{5} \mathrm{H}_{8} \mathrm{O}_{3}\right), \quad$ 1,2,4-cyclopentanetriol $\quad\left(\mathrm{C}_{5} \mathrm{H}_{10} \mathrm{O}_{3}\right) ;$ cyclotrtrasiloxane, and octamethyl $\left(\mathrm{C}_{8} \mathrm{H}_{24} \mathrm{O}_{4} \mathrm{Si}_{4}\right)$.

To investigate the effect of catalyst dosage and reaction temperature on cellulose conversion, catalyst dosage raging from $0.2 \mathrm{~g}$ to $0.4 \mathrm{~g}$ and reaction temperature ranging from $150^{\circ} \mathrm{C}$ to $190^{\circ} \mathrm{C}$ were tested. As seen in Figure 7 , catalyst dosage of $0.2 \mathrm{~g}$ (Figure $7(\mathrm{a})$ ) and reaction temperature at $170^{\circ} \mathrm{C}$ (Figure $7(\mathrm{~b})$ ) are optimal condition for cellulose conversion. The dosage of $0.2 \mathrm{~g}$ is sufficient for converting cellulose to 5-HMF, introduction of high dosage of $0.3 \mathrm{~g}$ $0.4 \mathrm{~g}$ leads to the catalyst excess which cause the further conversion of 5-HMF to the by product like levulinic, formic acid. The 4-HMF yield in the cellulose conversion to 5-HMF at $150^{\circ} \mathrm{C}$ increased with increasing reaction time from 0 to $4 \mathrm{~h}$ and then maintained unchanged for prolongation time to $6 \mathrm{~h}$. At higher temperature $\left(170^{\circ} \mathrm{C}\right), 5$-HMF yield increased because the reaction is thermodynamically favored at a high temperature. Further increase of temperature $\left(190^{\circ} \mathrm{C}\right)$ did not lead to the increase of 5-HMF yield but it decreased. This can be explained at very high temperature, glucose formed from cellulose hydrolysis is dehydrated forward the anhydroglucose which is thermodynamically favored at very high reaction temperature [29]. Moreover, prolongation of reaction time favored the formation of by-products including formic, acetic, levulinic, and glycollic acid [27].

\section{Conclusions}

Al-incorporated SBA-15 samples were successfully prepared by atomic implantation method. From XRD result, it revealed the mesoporous structure of Al-incorporated SBA15. TEM images showed that aluminium oxide species were well dispersed and located along the SBA-15 channels. Al incorporation into SBA-15 framework created the weak, medium, and strong acid sites.

Among Al-incorporated SBA-15 samples, 2Al/SBA-15 exhibited the highest yield of 5-HMF (yield 42\%). The yield obtained in this study is much higher to that reported in the literature.

\section{Data Availability}

The data used to support the findings of this study are available from the corresponding author upon request.

\section{Conflicts of Interest}

The authors declare that they have no conflicts of interest.

\section{Acknowledgments}

The authors thank the Vietnam Academy of Science and Technology (VAST) for financial support project (TĐPCCC.03/18-20).

\section{References}

[1] F. K. Kazi, A. D. Patel, J. C. Serrano-Ruiz, J. A. Dumesic, and R. P. Anex, "Techno-economic analysis of dimethylfuran (DMF) and hydroxymethylfurfural (HMF) production from pure fructose in catalytic processes," Chemical Engineering Journal, vol. 169, no. 1-3, pp. 329-338, 2011. 
[2] H. Yan, Y. Yang, D. Tong, X. Xiang, and C. Hu, "Catalytic conversion of glucose to 5-hydroxymethylfurfural over $\mathrm{SO}_{4}{ }^{2-}$ / $\mathrm{ZrO}_{2}$ and $\mathrm{SO}_{4}{ }^{2-} / \mathrm{ZrO}_{2}-\mathrm{Al}_{2} \mathrm{O}_{3}$ solid acid catalysts," Catalysis Communications, vol. 10, no. 11, pp. 1558-1563, 2009.

[3] J. Zhang, J. Li, and L. Lin, "Dehydration of sugar mixture to $\mathrm{HMF}$ and furfural over $\mathrm{SO}_{4}{ }^{2-} / \mathrm{ZrO}_{2}-\mathrm{TiO}_{2}$ catalyst," BioResources, vol. 9, no. 3, pp. 4194-4204, 2014.

[4] S. P. Ghuge and A. K. Saroha, "Ozonation of Reactive Orange 4 dye aqueous solution using mesoporous $\mathrm{Cu} / \mathrm{SBA}-15$ catalytic material," Journal of Water Process Engineering, vol. 23, pp. 217-229, 2018.

[5] S. Karthikeyan, M. P. Pachamuthu, M. A. Isaacs, S. Kumar, A. F. Lee, and G. Sekaran, "Cu and Fe oxides dispersed on SBA-15: a Fenton type bimetallic catalyst for N,N-diethyl- $p$ phenyl diamine degradation," Applied Catalysis B: Environmental, vol. 199, pp. 323-330, 2016.

[6] J. Fan, X. Jiang, H. Min et al., "Facile preparation of $\mathrm{Cu}-\mathrm{Mn}$ / $\mathrm{CeO}_{2} / \mathrm{SBA}-15$ catalysts using ceria as an auxiliary for advanced oxidation processes," Journal of Materials Chemistry A, vol. 2, no. 27, p. 10654, 2014.

[7] T. P. Dang, H. V. T. Nguyen, H. G. Le et al., "Fe-incorporation into mesoporous SBA-15 materials by direct synthesis and post-synthesis," in Proceedings of the SPIE 7267, Smart Materials V, vol. 726718, Melbourne, Australia, December 2008.

[8] C.-M. Yang, P.-H. Liu, Y.-F. Ho, C.-Y. Chiu, and K.-J. Chao, "Highly dispersed metal nanoparticles in functionalized SBA15," Chemistry of Materials, vol. 15, no. 1, pp. 275-280, 2003.

[9] E. Petala, K. Dimos, A. Douvalis et al., "Nanoscale zero-valent iron supported on mesoporous silica: characterization and reactivity for $\mathrm{Cr}(\mathrm{VI})$ removal from aqueous solution," Journal of Hazardous Materials, vol. 261, pp. 295-306, 2013.

[10] F. S. D. Santos, F. R. Lago, L. Yokoyama, and F. V. Fonseca, "Synthesis and characterization of zero-valent iron nanoparticles supported on SBA-15," Journal of Materials Research and Technology, vol. 6, no. 2, pp. 178-183, 2017.

[11] C. Zheng, C. Yang, X. Cheng et al., "Specifically enhancement of heterogeneous Fenton-like degradation activities for ofloxacin with synergetic effects of bimetallic $\mathrm{Fe}-\mathrm{Cu}$ on ordered mesoporous silicon," Separation and Purification Technology, vol. 189, pp. 357-365, 2017.

[12] M.-G. Seo, D.-W. Lee, K.-Y. Lee, and D. J. Moon, "Pt/Al-SBA15 catalysts for hydrocracking of $\mathrm{C}_{21}-\mathrm{C}_{34} n$-paraffin mixture into gasoline and diesel fractions," Fuel, vol. 143, no. 1, pp. 63-71, 2015.

[13] G. Muthu Kumaran, S. Garg, K. Soni et al., "Synthesis and characterization of acidic properties of Al-SBA-15 materials with varying $\mathrm{Si} / \mathrm{Al}$ ratios," Microporous and Mesoporous Materials, vol. 114, no. 1-3, pp. 103-109, 2008.

[14] J. Socci, A. Osatiashtiani, G. Kyriakou, and T. Bridgwater, "The catalytic cracking of sterically challenging plastic feedstocks over high acid density Al-SBA-15 catalysts," Applied Catalysis A: General, vol. 570, pp. 218-227, 2019.

[15] K. B. Baharudin, Y. H. Taufiq-Yap, J. Hunns, M. Isaacs, K. Wilson, and D. Derawi, "Mesoporous NiO/Al-SBA-15 catalysts for solvent-free deoxygenation of palm fatty acid distillate," Microporous and Mesoporous Materials, vol. 276, pp. 13-22, 2019.

[16] Z. Yang, W. Cai, J. Chou et al., "Hydrothermal synthesis of plugged micro/mesoporous Al-SBA-15 from spent fluid catalytic cracking catalyst," Materials Chemistry and Physics, vol. 222, no. 15, pp. 227-229, 2019.

[17] S. Xing, P. Lv, J. Fu et al., "Direct synthesis and characterization of pore-broadened Al-SBA-15," Microporous and Mesoporous Materials, vol. 239, pp. 316-327, 2017.
[18] Y. Li, W. Zhang, L. Zhang et al., "Direct synthesis of Al-SBA15 mesoporous materials via hydrolysis-controlled approach," Journal of Physical Chemistry B, vol. 108, no. 28, pp. 97399744, 2004.

[19] T. T. Nguyen, G. H. Le, C. H. Le et al., "Atomic implantation synthesis of $\mathrm{Fe}-\mathrm{Cu} / \mathrm{SBA}-15$ nanocomposite as a heterogeneous fenton-like catalyst for enhanced degradation of DDT," Materials Research Express, vol. 5, no. 11, article 115005, 2018.

[20] A. Vinu, T. Mori, and K. Ariga, "New families of mesoporous materials," Science and Technology of Advanced Materials, vol. 7, no. 8, pp. 753-771, 2006.

[21] S. More, R. Kadam, A. Kadam, D. Mane, and G. Bichile, "Structural properties and magnetic interactions in $\mathrm{Al}^{3+}$ and $\mathrm{Cr}^{3+}$ co-substituted $\mathrm{CoFe}_{2} \mathrm{O}_{4}$ ferrite," Open Chemistry, vol. 8, no. 2, pp. 419-425, 2010.

[22] X. Song, S. Li, K. Li et al., "Preparation of Cu-Fe composite metal oxide loaded SBA-15 and its capacity for simultaneous catalytic oxidation of hydrogen sulfide and phosphine," Microporous and Mesoporous Materials, vol. 259, pp. 89-98, 2018.

[23] K. Y. Nandiwale, N. D. Galande, P. Thakur, S. D. Sawant, V. P. Zambre, and V. V. Bokade, "One-pot synthesis of 5hydroxymethylfurfural by cellulose hydrolysis over highly active bimodal micro/mesoporous H-ZSM-5 catalyst," ACS Sustainable Chemistry \& Engineering, vol. 2, no. 7, pp. 1928-1932, 2014.

[24] C.-W. Jiang, X. Zhong, and Z.-H. Luo, "An improved kinetic model for cellulose hydrolysis to 5-hydroxymethylfurfural using the solid $\mathrm{SO}_{4}{ }^{2-} / \mathrm{Ti}-\mathrm{MCM}-41$ catalyst," RSC Advances, vol. 4, no. 29, pp. 15216-15224, 2014.

[25] A. Chareonlimkun, V. Champreda, A. Shotipruk, and N. Laosiripojana, "Catalytic conversion of sugarcane bagasse, rice husk and corncob in the presence of $\mathrm{TiO}_{2}, \mathrm{ZrO}_{2}$ and mixed-oxide $\mathrm{TiO}_{2}-\mathrm{ZrO}_{2}$ under hot compressed water (HCW) condition," Bioresource Technology, vol. 101, no. 11, pp. 4179-4186, 2010.

[26] A. Chareonlimkun, V. Champreda, A. Shotipruk, and N. Laosiripojana, "Reactions of $\mathrm{C}_{5}$ and $\mathrm{C}_{6}$-sugars, cellulose, and lignocellulose under hot compressed water (HCW) in the presence of heterogeneous acid catalysts," Fuel, vol. 89, no. 10, pp. 2873-2880, 2010.

[27] X. Qi, M. Watanabe, T. M. Aida, and R. L. Smith Jr., "Catalytical conversion of fructose and glucose into 5-hydroxymethylfurfural in hot compressed water by microwave heating," Catalysis Communications, vol. 9, no. 13, pp. 2244-2249, 2008.

[28] S. Wang, Y. Du, W. Zhang, X. Cheng, and J. Wang, "Catalytic conversion of cellulose into 5-hydroxymethylfurfural over chromium trichloride in ionic liquid," Korean Journal of Chemical Engineering, vol. 31, no. 10, pp. 1786-1791, 2014.

[29] V. Choudhary, R. I. Burnett, D. G. Vlachos, and S. I. Sandler, "Dehydration of glucose to 5-(hydroxymethyl) furfural and anhydroglucose: thermodynamic insights," Journal of Physical Chemistry C, vol. 116, no. 8, pp. 5116-5120, 2012. 

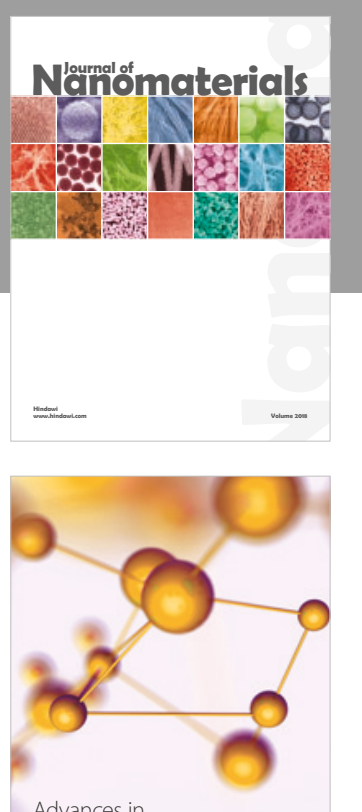

Physical Chemistry
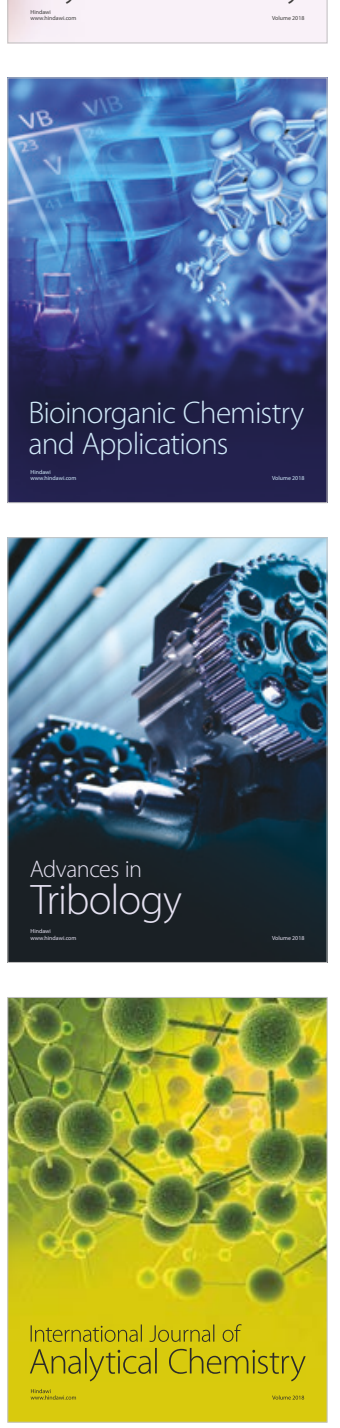

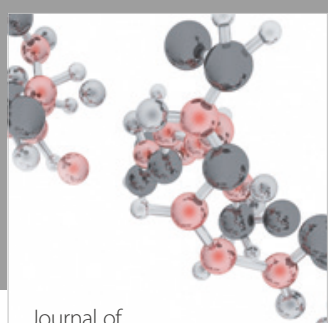

Analytical Methods

in Chemistry

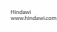

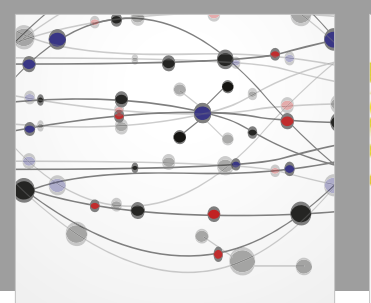

The Scientific World Journal

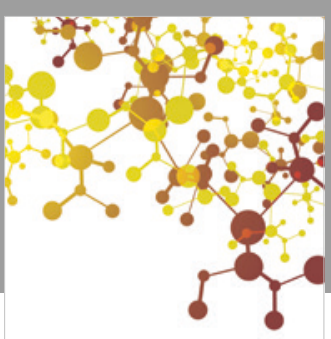

Journal of

Applied Chemistry
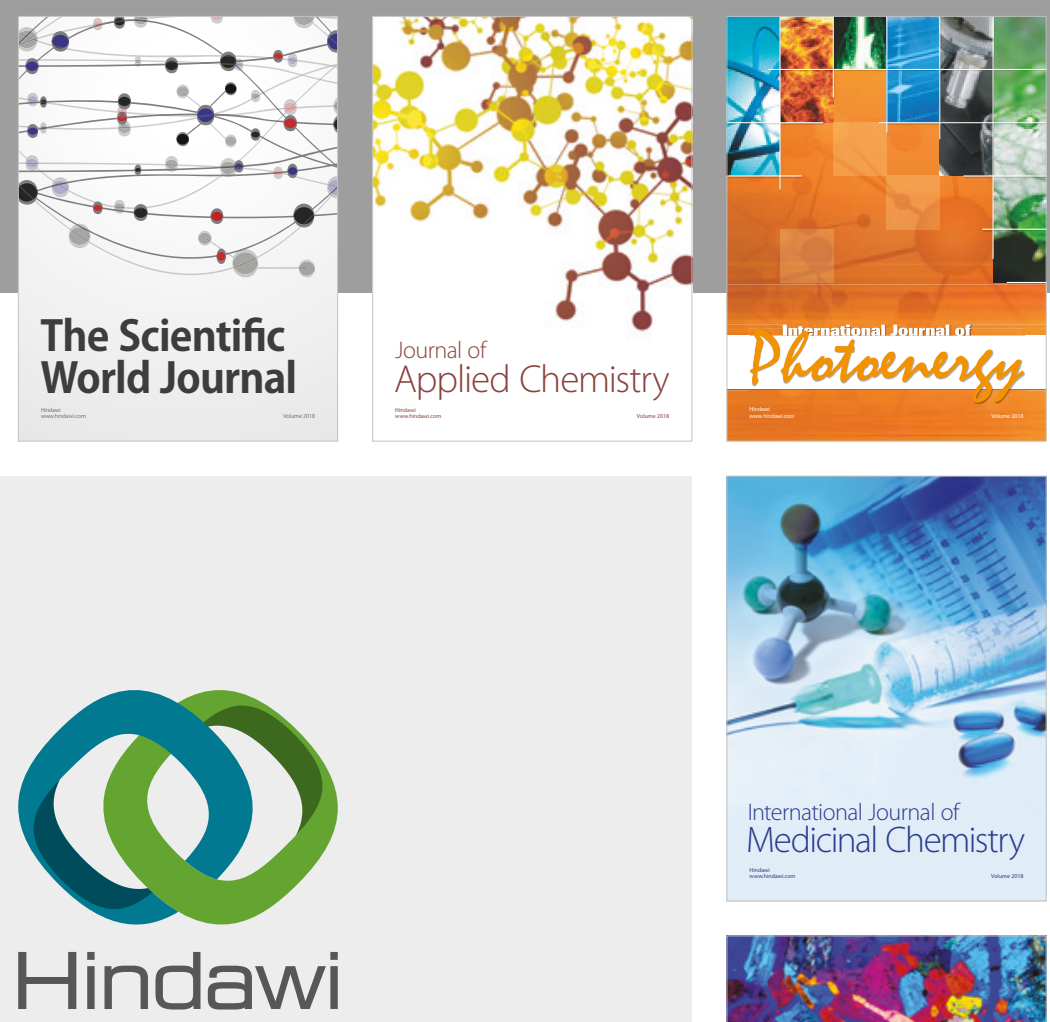

Submit your manuscripts at

www.hindawi.com
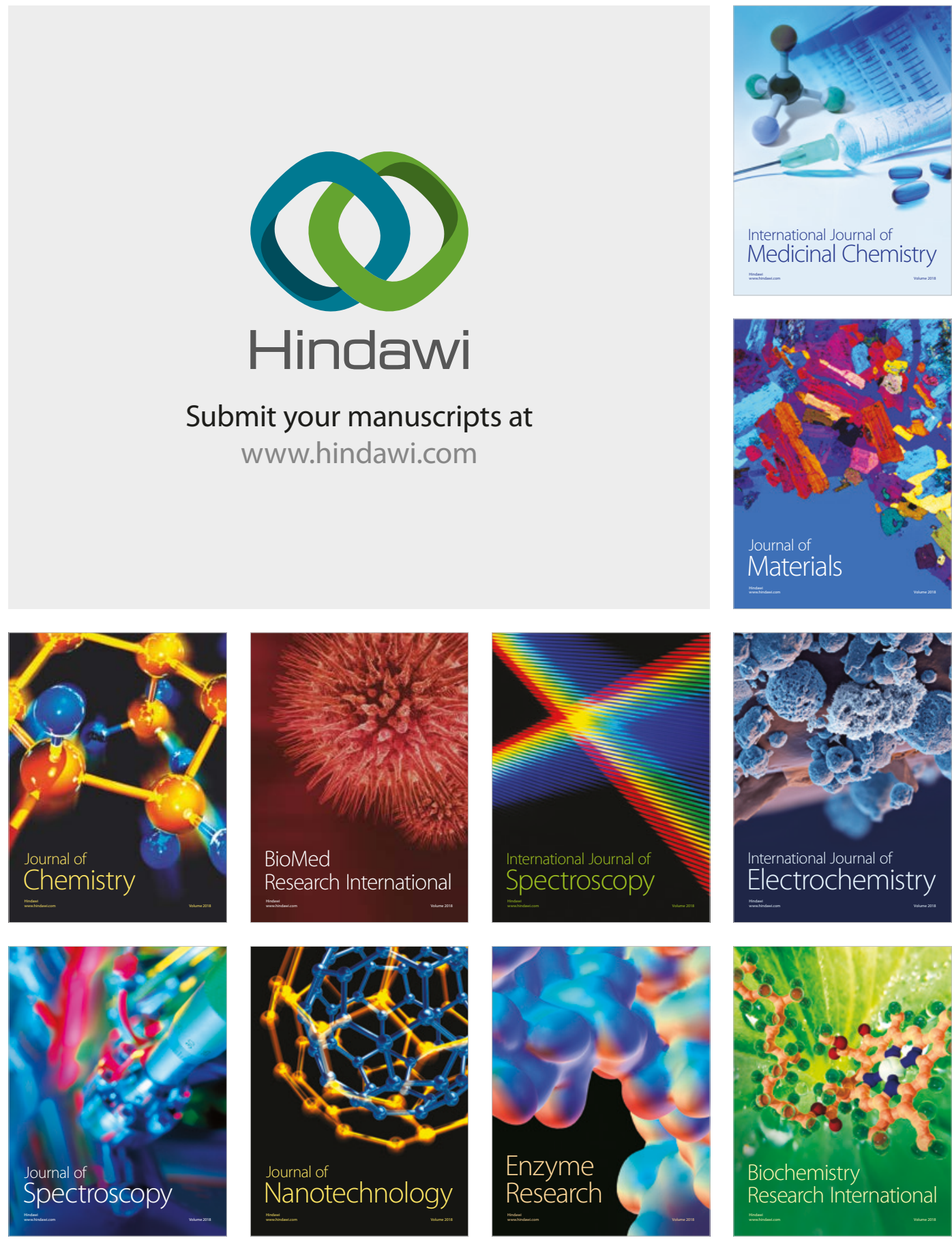
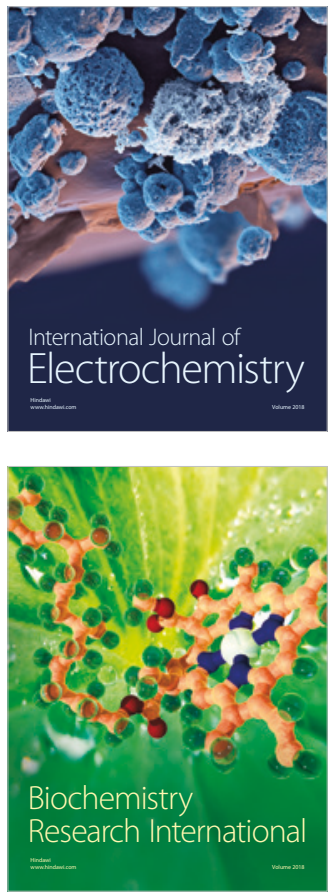